\title{
Normal peak nasal inspiratory flow rate values in healthy children aged 6 to 11 years in the Netherlands*
}

\section{E. van Spronsen", F.A. Ebbens", W.J. Fokkens}

Department of Otorhinolaryngology, Academic Medical Center, Amsterdam, the Netherlands
Rhinology 50: 21-25, 2012

DOI: 10.4193/Rhino.09.119

*Received for publication:

June 15, 2009

accepted: August 10, 2010

"Both authors contributed equally

to this manuscript

\section{Summary}

Background: The measurement of peak nasal inspiratory flow (PNIF) is a simple, quick, easy to perform and cheap tool for determining the extent of nasal airway patency. However, normative data are rare and not available for Dutch children aged 6 to 11 years.

Methods: Repeated PNIF measurements were obtained from 212 Dutch children of primary school age. Of these 212 children, 166 fulfilled the inclusion criteria of our study. The influence of age, gender, ethnicity, weight and height on PNIF was studied.

Results: Age is the only parameter of influence on PNIF. All other parameters do not influence PNIF. Normative data are presented.

Conclusion: PNIF measurements are possible in children aged six years and older. Age does influence PNIF, but gender, weight, height and ethnicity do not.

Key words: PNIF, children, nose, congestion, normative data, nasal patency, age

\section{Introduction}

Nasal obstruction is of increasing interest to many clinicians as it is a common symptom of nasal pathology ${ }^{(1)}$. Nasal obstruction has been shown to correlate with decreased quality of life as a result of, amongst others, decreased quality of sleep, (chronic) rhinosinusitis, otitis media and asthma (2). Infants and children frequently present themselves to both primary and secondary care clinicians with nasal airway obstruction. In many children, however, perceived and observed nasal patency values do not correlate. Priftis et al. have shown, for example, that children on long-term treatment for chronic rhinitis underreport the amount of nasal congestion they are bothered by (3). In addition, only weak correlations between allergic rhinitis symptoms and objective measurements of nasal obstruction were observed by Gomes et al. ${ }^{(4)}$. Therefore, objective assessment tools are required. Fortunately, various tools are available including rhinomanometry, acoustic rhinometry and PNIF. Although normative values for rhinomanometry ${ }^{(5)}$ and acoustic rhinometry ${ }^{(6,7)}$ are available, both rhinomanometry and acoustic rhinometry require highly trained operators and expensive equipment. In addition, both rhinomanometry and acoustic rhinometry are time consuming, limiting their use in clinical practice ${ }^{(8)}$. PNIF is easy to use and values have been shown to correlate well with nasal airway resistance ${ }^{(9)}$. In addition, PNIF values have been shown to be equal to rhinomanometry in determining nasal patency ${ }^{(10)}$. Although normative data have 
been established in adults ${ }^{(11,12)}$, few data are available on PNIF values in children. To our knowledge, only two studies are currently available presenting normative PNIF values in children. In the first study, performed in South Africa, children below the age of eight years were included ${ }^{(13)}$. In the second study, performed in Greece, children aged 5 to 18 years were included (14). Currently, no normative PNIF rate values are available for healthy Dutch children. With this in mind, we performed the current study.

\section{Material And Methods}

Participants

Recruitment of children took place in December 2007 and January 2008 on two occasions (science day at our institute, visit to a local primary school). Prior to inclusion, demographic details (including the subject's date of birth, height, weight, gender, and (if possible) ethnic origin), a general medical history and ENT history (including a history of previous ENT surgery) and informed consent were obtained from each child and his or her parent and/or supervisor. All individuals suffering from allergic rhinitis and/or asthma were excluded. In addition, all individuals suffering from a current episode of an upper respiratory tract infection were excluded. Those individuals with a previous history of an adenotonsillectomy were excluded from participation. Current use of topical and/or oral anti-histamines and/or corticosteroids was not allowed. Each subject was allowed to voluntarily discontinue participation at any time. If necessary, the investigator was allowed, at his or her discretion, to discontinue a subject from participation at any time.

\section{Assessment of nasal patency}

A portable Youlten peak flow meter (Clement Clark International) was used for the measurement of peak inspiratory nasal flow. The masks attached to the Youlten peak flow meter were fit tightly to each subject's face without touching the nose. All subjects were tested while seated. At the end of a full expiration, individuals were encouraged to inhale through their nose as hard and fast as they could keeping their mouth closed [residual volume (RV) method]. Three correctly performed measurements were recorded. Highest values (L/min) were used for further analysis.

\section{Statistical analysis}

Statistical analysis was performed using SPSS 16.0 (Chicago, IL, USA). Chi-square analyses were performed to check for an interaction between gender or ethnicity and PNIF. Since gender and ethnicity were shown not to influence PNIF values, a regression analysis was performed to study the interaction between age, weight, height and PNIF. Since age, weight and height were shown to have a linear relationship with PNIF using scatter- plots, a linear regression model was allowed. Paired samples T-tests were performed to check for learning effects in PNIF due to repeated PNIF measurements. P values of 0.05 were considered statistically significant.

\section{Results}

In total, 212 healthy children aged 6 to 13 years without nasal airway obstruction (subjective assessment) were recruited. As most children in primary school are between the age of 6 and 11 and only 11 individuals above the age of 11 were included, those children above the age of 11 were excluded from further analyses. All individuals suffering from allergic rhinitis and/ or asthma were excluded. In addition, all individuals suffering from an upper respiratory tract infection were excluded. Those individuals with a previous history of an adenotonsillectomy were excluded from participation. Current use of topical and/ or oral anti-histamines and/or corticosteroids was not allowed. Thus, 166 children were included for subsequent analyses. Figure 1 summarizes PNIF rate values for children between the age of 6 and 11 years.

Effect of gender and ethnicity on PNIF In total, 88 female children (53.0\%) and 78 male children (47.0\%) were included. Although PNIF rates were slightly higher in females aged 6 and 7 years and males aged 8 to 11 years, we observed no significant differences between both groups ( $p=$ 0.200 ). Ethnic background was noted in children studied on the second study day at a local primary school only $(n=64) .68 .8 \%$ of these children were of Caucasian (i.e. Dutch) background. Smaller percentages of children were of African (i.e. originating from countries below the Sahara and Suriname) descent (14.1\%), Mediterranean (i.e. originating from Turkey, Morocco and Egypt) descent (12.5\%) and Asian (i.e. originating from China and Indonesia) descent (4.7\%). Ethnicity was shown not to differ between male and female children $(p=0.208)$ and not to influence PNIF ( $p=0.428)$.

\section{Effect of age, weight and height on PNIF}

Using a linear regression model including age, weight and height as possible factors, age was shown to significantly influence PNIF ( $p=0.019)$. Both weight $(p=0.342)$ and height $(p=$ 0.080 ) were shown not to influence outcome.

\section{Effect of repeated PNIF measurements}

As three PNIF attempts were allowed, one may assume that a learning effect is present. Indeed, when comparing PNIF rates of the first and second attempt $(p=0.000)$, the first and third attempt $(p=0.000)$ and second and third attempt $(p=0.024)$, a slight increase in PNIF is observed upon each attempt (Figure 2 ), suggesting a learning effect. 


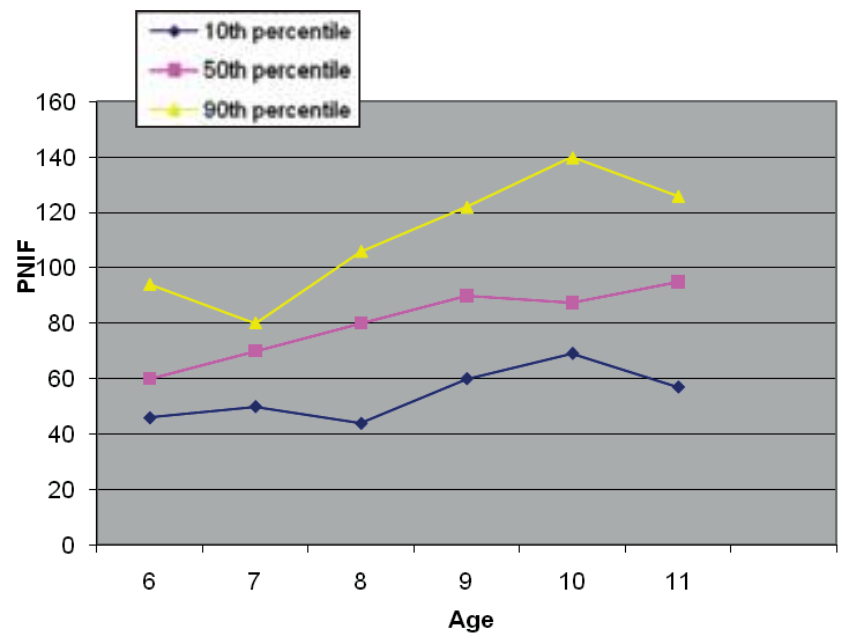

Figure 1. Normative PNIF values for children aged 6 to 11 years.

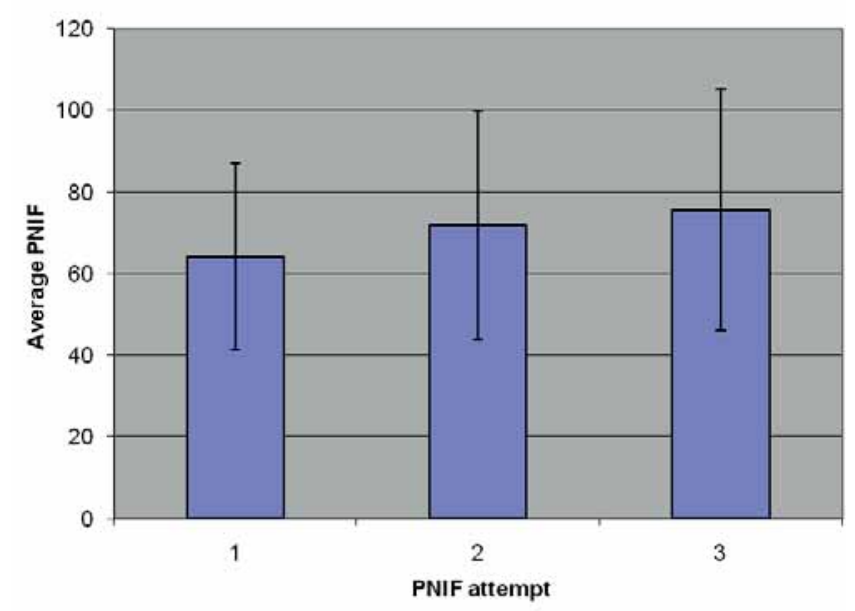

Figure 2. Comparison of average (SD) PNIF values and attempt.

\section{Discussion}

PNIF is a simple, quick, easy to perform and cheap method for the assessment of nasal patency. Although normative data are available for many years for adults ${ }^{(11,12)}$, this is the second study to describe normative PNIF rates in healthy children aged 6 to 11 years, values that can be used to assess the extent of nasal obstruction and the effect of treatment aimed at an improvement of nasal patency in children aged 6 to 11 years.

The routine use of PNIF in children depends on the acceptance of repeated PNIF measurements. In contrast to what has been described by Prescott et al. ${ }^{(13)}$, when correctly instructed, we demonstrate that, even young children, repeated PNIF measurements are possible. In our study, the majority of children actually enjoyed the assessment of PNIF rates. It may well be, that the location of testing (in our case a school and in Prescott's case a hospital) explains the observed difference in acceptance of repeated PNIF measurements.

The PNIF rates obtained in this study are, to our opinion, a good representation of PNIF rates in healthy children aged 6 to 11 years in the Netherlands. Although it has been suggested that age, gender, height, weight and ethnic background all influence PNIF rates in children aged 6 to 11 years, we show that only age significantly influences outcome. A similar effect of age on PNIF rates in children has been observed by both Prescott et al. and Papachristou et al. ${ }^{(13,14)}$. The presence of an age effect in adults is controversial ${ }^{(11,15)}$.

We observed no correlation between PNIF rates and weight and/or height. This observation is similar to observations in adults by Blomgren et al. ${ }^{(15)}$. However, in children aged 3 to 8 years, Prescott et al. demonstrated a correlation between PNIF and weight and/or height ${ }^{(13)}$. The younger age and/or the larger variation in weight and/or height in their study may explain the observed differences.

Although slightly higher PNIF rates were observed in females aged 6 and 7 years and boys aged 8 to 11 years, differences were not significant. Similar results have been observed by Papachristou et al. who showed slightly higher PNIF rates in females aged 5 years and slightly higher PNIF rates in males aged 6 to 12 years with no significant differences between the two gender groups ${ }^{(14)}$. Above the age of 12 years, PNIF rate values have been reported to be significantly higher in male children ${ }^{(14)}$.

As has been described previously, we demonstrate that the PNIF procedure is characterized by a learning curve ${ }^{(13)}$. We show that PNIF values significantly increase with each attempt in children aged 6 to 11 years with highest values on average recorded during the third attempt. This suggests that more than three attempts are required in children aged 6 to 11 years to reach the plateau phase. Future studies are necessary to confirm this hypothesis.

In summary, we conclude that PNIF measurements are possible in children aged six years and older and that age, but not gender, weight, height and ethnicity, does influence PNIF in healthy Dutch children. 


\section{References}

1. van Spronsen E, Ingels KJ, Jansen AH, Graamans K, Fokkens WJ. Evidence-based recommendations regarding the differential diagnosis and assessment of nasal congestion: using the new GRADE system. Allergy. 2008; 63: 820-833.

2. Corey JP, Houser SM, Ng BA. Nasal congestion: a review of its etiology, evaluation, and treatment. Ear Nose Throat J. 2000; 79: 690-693, 696, 698.

3. Priftis KN, Drigopoulos K, Sakalidou A, Triga M, Kallis V, Nicolaidou P. Subjective and objective nasal obstruction assessment in children with chronic rhinitis. Int J Pediatr Otorhinolaryngol. 2006: 70: 501-505.

4. Gomes DdeL, Camargos PA, Ibiapina CdaC, Andrade de CR. Nasal peak inspiratory flow and clinical score in children and adolescents with allergic rhinitis. Rhinology. 2008; 46: 276280.

5. Zapletal A, Chalupova J. Nasal airflow and resistance measured by active anterior rhinomanometry in healthy children and adolescents. Pediatr Pulmonol. 2002; 33: 174-180.

6. Straszek SP, Schlunssen V, Sigsgaard T, Pedersen OF. Reference values for acoustic rhinometry in decongested school children and adults: the most sensitive measurement for change in nasal patency. Rhinology. 2007; 45: 36-39.
7. Straszek SP, Moeller A, Hall GL, Zhang G, Stick SM, Franklin PJ. Reference values for acoustic rhinometry in children from 4 to 13 years old. Am J Rhinol. 2008; 22: 285-291.

8. Malm L, Gerth van Wijk R, Bachert C. Guidelines for nasal provocations with aspects on nasal patency, airflow, and airflow resistance. International Committee on Objective Assessment of the Nasal Airways, International Rhinologic Society. Rhinology. 2000; 38: 1-6.

9. Frolund L, Madsen F, Mygind N, Nielsen $\mathrm{NH}$ Svendsen UG, Weeke B. Comparison between different techniques for measuring nasal patency in a group of unselected patients. Acta Otolaryngol. 1987; 104: 175-179

10. Gleeson MJ, Youlten $\perp$, Shelton DM, Siodlak MZ, Eiser NM, Wengraf CL. Assessment of nasal airway patency: a comparison of four methods. Clin Otolaryngol Allied Sci. 1986; 11: 99-107.

11. Ottaviano G, Scadding GK, Coles S, Lund VJ. Peak nasal inspiratory flow; normal range in adult population. Rhinology. 2006; 44: 32-35

12. Ottaviano G, Lund VJ, Coles S, Staffieri A, Scadding GK. Does peak nasal inspiratory flow relate to peak expiratory flow? Rhinology. 2008; 46: 200-203.

13. Prescott CA, Prescott KE. Peak nasal inspiratory flow measurement: an investigation in children. Int J Pediatr Otorhinolaryngol. 1995; 32: 137-141
14. Papachristou A, Bourli E, Aivazi D, Futzila E, Papastavrou Th, Konstandinidis Th, Maratou E, Ilonidis G, Aivazis V. Normal peak nasal inspiratory flow rate values in Greek children and adolescents. Hippokratia. 2008; 12: 94-102.

15. Blomgren K, Simola M, Hytonen M, Pitkaranta A. Peak nasal inspiratory and expiratory flow measurements--practical tools in primary care? Rhinology. 2003; 41: 206-210.

E. van Spronsen, MD MSc

Department of Otorhinolaryngology, Head \& Neck Surgery Academic Medical Center Meibergdreef 9 1105 AZ Amsterdam the Netherlands

Tel: +31-20-566 3789

Fax: +31-20-566 9573

E-mail: e.vanspronsen@amc.uva.nl

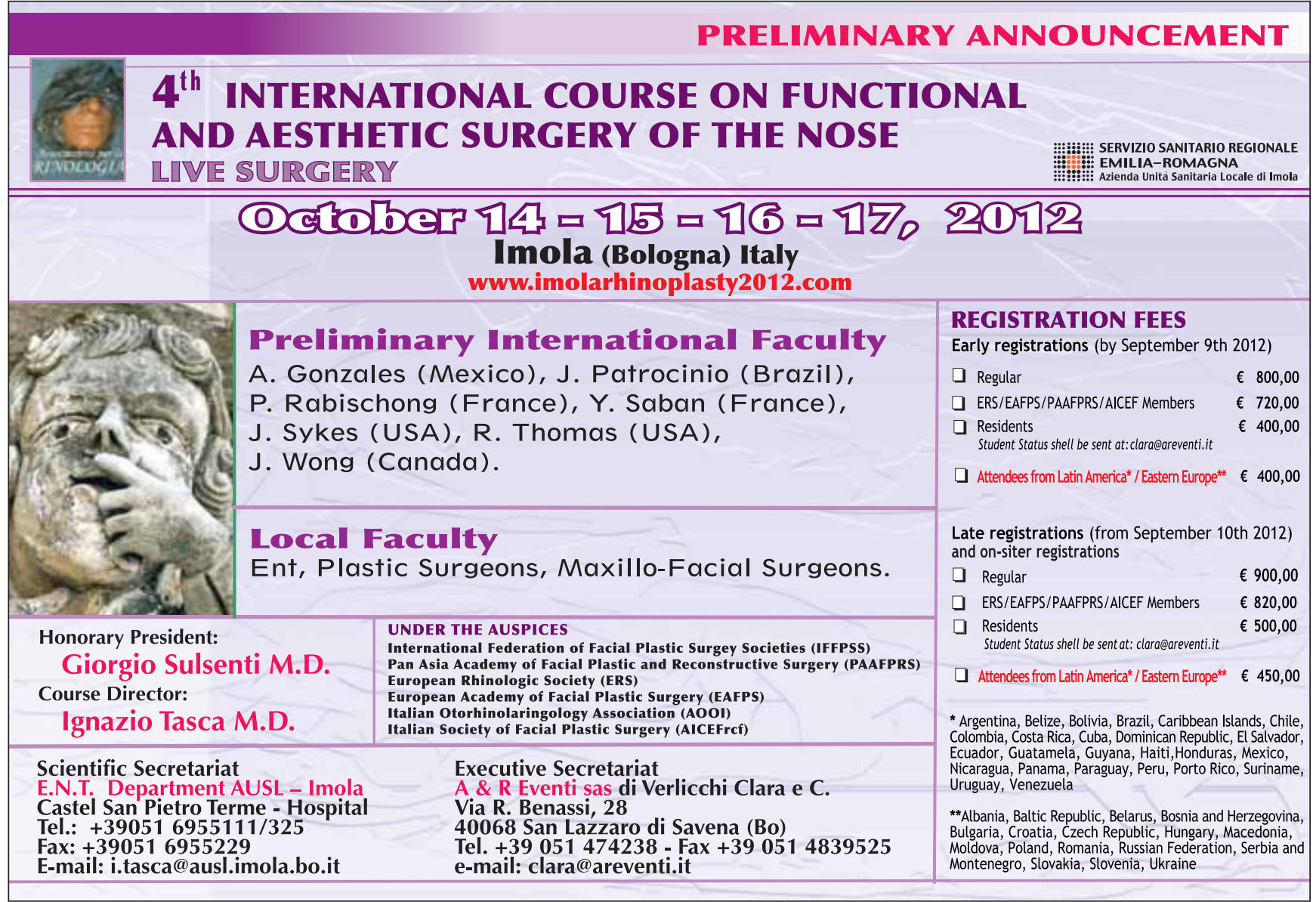

